Check for updates

Cite this: Phys. Chem. Chem. Phys., 2018, 20, 24591

Received 12th June 2018 Accepted 10th September 2018

DOI: $10.1039 / c 8 c p 03724 h$

rsc.li/pccp

\section{Intermolecular interactions upon carbon dioxide capture in deep-eutectic solvents $\dagger$}

\begin{abstract}
Shashi Kant Shukla (D)*a and Jyri-Pekka Mikkola*ab
Herein we report the $\mathrm{CO}_{2}$ uptake in potential deep-eutectic solvents (DESs) formed between hydrogen bond acceptors (HBAs) such as monoethanolammonium chloride ([MEA.Cl]), 1-methylimidazolium chloride ([HMIM.CI]) and tetra- $n$-butylammonium bromide ([TBAB]) and hydrogen bond donors (HBDs) like ethylenediamine ([EDA]), diethylenetriamine ([DETA]), tetraethylenepentamine ([TEPA]), pentaethylenehexamine ([PEHA]), 3-amino-1-propanol ([AP]) and aminomethoxypropanol ([AMP]) and analyzed the outcome in terms of the specific polarity parameters. Among various combinations of HBAs and HBDs, [MEA.CI][EDA]-, [MEA.CI][AP]-, [HMIM.CI][EDA]- and [HMIM.CI][AP] showed excellent $\mathrm{CO}_{2}$ uptake which was further improved upon increasing the mole ratio of $\mathrm{HBA}: \mathrm{HBD}$ from 1:1 to 1:4. The lowest $\mathrm{CO}_{2}$ uptake in [MEA.CI][PEHA] (12.7 wt\%) and [HMIM.Cl][PEHA] (8.4 wt\%) despite the highest basicity of [PEHA] infers that the basicity is not the sole criteria for guiding the $\mathrm{CO}_{2}$ uptake but, in reality, $\mathrm{CO}_{2}$ capture in a DES relies on the interplay of $\mathrm{H}$-bonding interactions between each HBA and HBD. The role of HBAs in guiding $\mathrm{CO}_{2}$ uptake was more prominent with weak HBDs such as [TEPA] and [PEHA]. The speciation of absorbed $\mathrm{CO}_{2}$ into carbamate, carbonate, and bicarbonate was favorable in DES characterized by comparable hydrogen bond donor acidity $(\alpha)$ and hydrogen bond acceptor basicity $(\beta)$ values, whereas the conversion of carbamate to carbonate/bicarbonate was observed to depend on $\alpha$. The addition of water in DES resulted in lower $\mathrm{CO}_{2}$ uptake due to the decreased basicity $(\beta)$.
\end{abstract}

\section{Introduction}

Carbon dioxide $\left(\mathrm{CO}_{2}\right)$ emissions due to anthropogenic activities have been constantly increasing over the past century and gaining worldwide attention due to the deleterious action of this notorious greenhouse gas. Subsequently, to develop materials that selectively, efficiently and inexpensively capture $\mathrm{CO}_{2}$ is of great importance. ${ }^{1-3}$ Among various methods proposed to reduce anthropogenic $\mathrm{CO}_{2}$ emissions, a carbon dioxide capture and sequestration (CCS) process that incorporates both physical and chemical adsorptions and absorption rely heavily on the concept of using alkanolamine-based solvents. Typical solutions involved include monoethanolamine (MEA) and methyldiethylamine (MDEA) and their aqueous solutions. ${ }^{4}$ Despite their wide acceptability, several disadvantages linger with MEA- and MDEA-based technologies such as their volatility, high cost, substantial energy consumption and corrosiveness. These shortcomings

\footnotetext{
${ }^{a}$ Technical Chemistry, Department of Chemistry, Chemical-Biological Centre, Umeå University, SE-90187 Umeå, Sweden. E-mail: shashi.kant.shukla@umu.se, jyri-pekka.mikkola@umu.se

${ }^{b}$ Industrial Chemistry \& Reaction Engineering, Department of Chemical Engineering, Johan Gadolin Process Chemistry Centre, Åbo Akademi University, FI-20500 Åbo-Turku, Finland

$\dagger$ Electronic supplementary information (ESI) available. See DOI: 10.1039/ c8cp03724h
}

pose a potential threat to human health and critical mutilations to the environment. ${ }^{5}$ As a result, the design of alternative materials for $\mathrm{CO}_{2}$ capture is of high importance and has garnered much attention in the last decade. ${ }^{6}$

Among the many possibilities, ionic liquids (ILs) have been extensively investigated as promising candidates because of their several advantageous properties to substitute the traditional scrubbing agents for reversible $\mathrm{CO}_{2}$ capture. ${ }^{7}$ In this regard, a variety of ILs containing pyridinium, imidazolium, guanidinium, amine-functionalized cation and inorganic/organic anion have been examined and the basicity of the anion has been identified to play a major role upon $\mathrm{CO}_{2}$ capture ${ }^{8-14}$ following semimolar or multi-molar mechanism. ${ }^{15,16}$ However, the multi-molar $\mathrm{CO}_{2}$ absorption in ILs became less attractive when converted to the gravimetric uptake values. ${ }^{13,16,17}$ For example, dual aminofunctionalized cation-tethered IL, capable of absorbing an equimolar amount of $\mathrm{CO}_{2}$ exhibited only $18.5 \mathrm{wt} \%$ capacity on the gravimetric scale. ${ }^{18}$ Moreover, high viscosities, unfavorable energy consumption and the high cost of starting materials still hint that ILs are further inapt for large scale applications. ${ }^{19,20}$

In quest of the sustainable solvents, deep-eutectic solvents (DESs) has been extensively explored in the last decade. DESs are eutectic mixtures of Lewis or Brønsted acids also called as HBA and bases/HBDs and can contain a variety of anionic and/or cationic species and therefore exhibit properties similar to ILs. ${ }^{21}$ 
DES can be prepared by a single-step atom-economic reaction under solvent-free conditions and does not require further purification thereby simplifying the scale up for various processes. $^{22}$ The hydrogen bonding strength via charge delocalization between the HBA and HBD component is responsible for the relative difference in the melting point of the eutectic mixture and thus, a variety of potential DES can be easily prepared by varying the strength and molar ratios of the HBD and HBA substituents. ${ }^{23,24}$

DES's efficacy in gas absorption was recognized after the pioneering work of Zhu et al., who employed choline chloride $(\mathrm{ChCl})+$ urea as a heterogeneous sorbent and catalyst upon chemical fixation of $\mathrm{CO}_{2}$ to cyclic carbonates. ${ }^{25} \mathrm{Li}$ et al. measured the $\mathrm{CO}_{2}$ solubility at various temperatures and pressures in $\mathrm{ChCl}+$ urea-based DESs, at different mole ratios. $^{26}$ Later, different combinations of HBD (urea, lactic acid, glycerol etc.) and HBA (tetraalkylammonium/phosphonium halides, choline chloride etc.) components were tried to optimize the $\mathrm{CO}_{2}$ uptake capacity in DESs but the molar capability of all the tested DESs remained in the range of $0.02-0.14$ mole per mole of DES with the highest value equivalent to $7 \mathrm{wt} \% .^{27-30}$ Mirza et al. measured $\mathrm{CO}_{2}$ solubility in three DESs reline, ethaline and malinine in the temperature range $309-329 \mathrm{~K}$ and at pressure up to $160 \mathrm{kPa}^{31}$ The modified Peng-Robinson equation of state was used to correlate the experimental data. The thermodynamic parameters derived from the equation suggested $\mathrm{CO}_{2}$ absorption as a nonspontaneous exothermic process. ${ }^{31}$ Very recently, Trivedi et al. reported $33.7 \mathrm{wt} \%$ of $\mathrm{CO}_{2}$ in [MEA.Cl][EDA] formed at $1: 3$ mole ratio, at $30{ }^{\circ} \mathrm{C}^{32}$ The large $\mathrm{CO}_{2}$ uptake in [MEA.Cl][EDA]-based DESs was assumed to depend on the change in polarity and basicity, although a direct correlation between the actual polarity parameters and $\mathrm{CO}_{2}$ uptake was absent. ${ }^{32}$

To the best of our knowledge, so far no report discussing the role of intermolecular interactions on $\mathrm{CO}_{2}$ capture and speciation of absorbed $\mathrm{CO}_{2}$ in ILs and DESs can be found in open literature. The solvatochromic polarity parameters include electronic transition energy $\left(E_{\mathrm{T}}(30)\right)$, hydrogen bond donor acidity $(\alpha)$, hydrogen bond acceptor basicity $(\beta)$ and, dipolarity/polarizability $\left(\pi^{*}\right) \cdot{ }^{33-36}$ The $E_{\mathrm{T}}(30)$ measures various possible directional and nondirectional solute-solvent interactions between Reichardt's dye (30) and solvent molecules and can be determined by using the absorption maxima of Reichardt's dye 30 . The dipolarity/ polarizability $\left(\pi^{*}\right)$ parameter denotes the electrolytic strength of the DES and relies on the interaction of probe molecule with its cybotactic environment and can be determined from the spectroscopic shift of $N, N$-diethyl-4-nitroaniline. The hydrogen bond acceptor tendency $(\beta)$ exhibits the basicity of the hydrogen bond donor (HBD) component of DES and can be determined by using the spectroscopic shift of 4-nitroaniline with respect to $N, N$-diethyl-4-nitroaniline. The hydrogen bond donor acidity $(\alpha)$ denotes the donating ability of the hydrogen bond acceptor (HBA) component of DES and can be obtained by employing $E_{\mathrm{T}}(30)$ and $\pi^{*}$. The empirical equations to obtain various polarity parameters are given in Table 2 . These polarity parameters $\left(E_{\mathrm{T}}(30), \alpha, \beta\right.$ and $\left.\pi^{*}\right)$ can be employed as a tool for accounting the influence of intermolecular solute-solvent interactions upon various physical and chemical changes. $^{37}$

Recently, Shukla and Kumar have used solvatochromic polarity parameters during the Hammett acidity $\left(H_{0}\right)$ measurements to discuss the role of intermolecular interactions on the dissociation of aqueous carboxylic acids in protic ionic liquids. ${ }^{38}$ The acidity-polarity correlation was further supported by thermodynamic parameters $\left(\Delta H^{0}\right.$ and $\left.\Delta S^{0}\right) \cdot{ }^{38}$ Liu et al. discussed the role of intermolecular interaction upon $\mathrm{CO}_{2}$ capture $(0.7551 \mathrm{~mol} \mathrm{CO}$ per mol DES) in the 1,3-butanediol + 1,3-ethanediamine system in terms of excess molar volume $\left(V_{\mathrm{M}}^{\mathrm{E}}\right)$, viscosity deviations $(\Delta \eta)$ and apparent molar volumes $\left(V_{\varphi, 1}\right.$ and $\left.V_{\varphi, 2}\right)$, from density and viscosity values measured at different temperatures and compositions. ${ }^{39}$ Contrary to the excess properties, polarity parameters have the advantage in terms of predicting the nature and specificity of the interactions.

In the present work, we have attempted to investigate the role of intermolecular interactions on $\mathrm{CO}_{2}$ capture and its speciation into the carbamate, carbonate, and bicarbonate in potential DESs. For this purpose, the gravimetric $\mathrm{CO}_{2}$ uptakes in these DESs are analyzed in terms of the $E_{\mathrm{T}}(30), \alpha, \beta$, and $\pi^{*}$ values. The adverse effect of viscosity on $\mathrm{CO}_{2}$ absorption is also taken into account while correlating the polarity parameters with $\mathrm{CO}_{2}$ wt\%. The structure of HBD and HBA components of DESs are shown in Table 1. The structure of different solvatochromic dyes involved in the polarity determinations is shown in Fig. 1.

\section{Experimental section}

\section{Materials}

The spectroscopic indicator dye 2,6-diphenyl-4-(2,4,6-triphenylpyridinium-1-yl)-phenolate (1), 4-nitroaniline (2), N,N-diethyl-4nitroaniline (3) and monoethanolamine, 1-methylimidazole, tetrabutylammonium bromide, 3-amino-1-propanol, aminomethylpropanol, ethylenediamine, diethyltetramine, triethylenepentamine, and pentaethylhexamine were procured from Sigma-Aldrich and used without further purification. Hydrochloric acid was obtained from Merck.

\section{Synthesis of DESs}

Monoethanolamine (MEA)- and 1-methylimidazole(MIM)-based DESs were synthesized by protonation-complexation processes. Protonation involved the drop-wise addition of aqueous hydrochloric acid into the MEA and MIM, maintained at $273 \mathrm{~K}$ under vigorous stirring. The resultant protic ionic liquids (PILs) were first placed under rotary-evaporator at $60{ }^{\circ} \mathrm{C}$ and later connected to the ultra-high vacuum pump operated at $70{ }^{\circ} \mathrm{C}$ to remove all traces of water and other volatile impurities. Complexation comprised addition of various HBDs in PILs at $80{ }^{\circ} \mathrm{C}$ for $1 \mathrm{~h}$, to yield the desired DESs. The TBAB-based DESs were prepared by complexing the TBAB with different HBDs at $80{ }^{\circ} \mathrm{C}$ for $1 \mathrm{~h}$. The pictorial representation of the DESs synthesis is shown in Scheme 1. All DESs and their precursors were characterized by ${ }^{1} \mathrm{H}$ NMR- and ${ }^{13} \mathrm{C}$ NMR-spectroscopy (see ESI $\dagger$ ). 
Table 1 Structure of DESs employed in $\mathrm{CO}_{2}$ capture and polarity determination

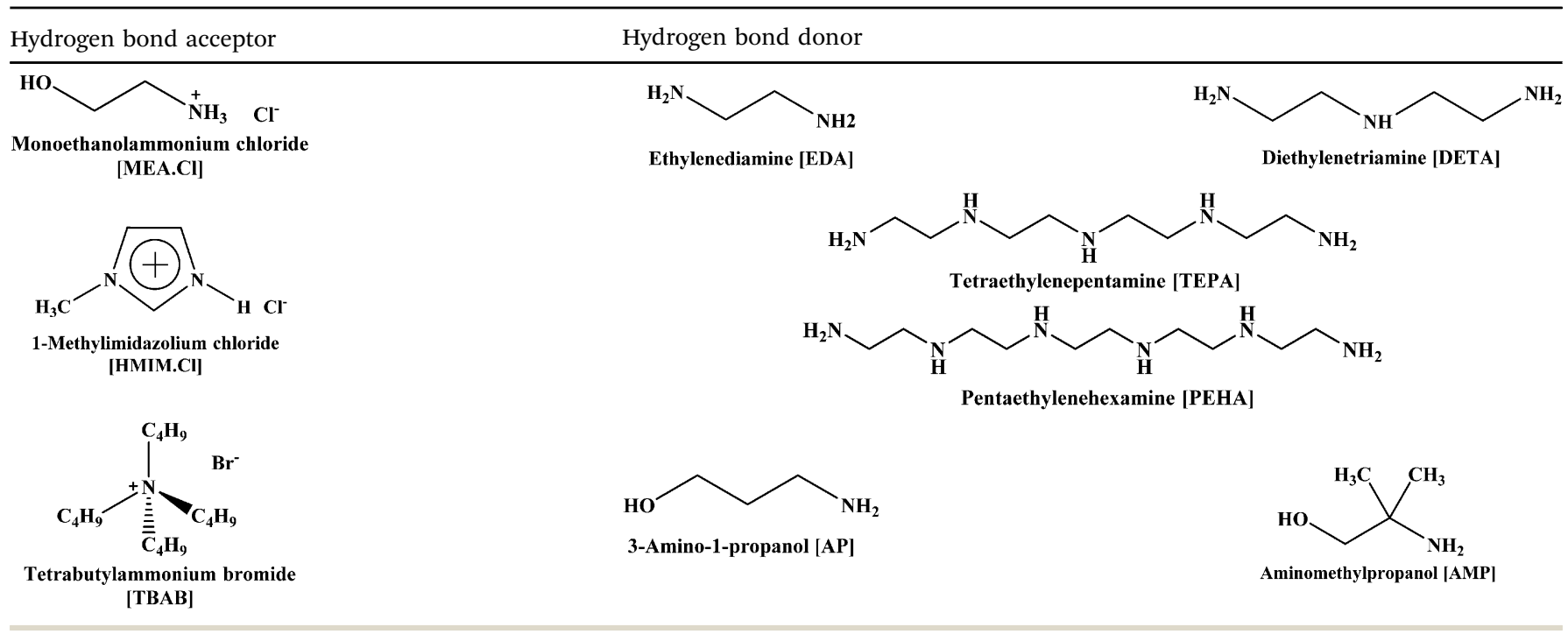<smiles></smiles>

2,6-dichloro-4-(2,4,6-triphenyl-pyridinium-1-yl)phenolate (1)<smiles>Nc1ccc([N+](=O)[O-])cc1</smiles><smiles>CCN(CC)c1ccc(N)cc1</smiles>

$N, N$-diethyl-4-nitroaniline (3)

Fig. 1 Structure of the solvatochromic probe molecules.

\section{Determination of polarity parameters}

All solvatochromic dyes were dissolved in methanol to prepare a stock solution $\left(10^{-2} \mathrm{M}\right)$ prior to the polarity measurements. The stock solution was taken in a glass vial first and methanol was removed by blowing nitrogen gas into the vial followed by the addition of $1 \mathrm{ml}$ of DESs. Consequently, the resultant solution was transferred into a $1.3 \mathrm{ml}$ quartz cuvette under nitrogen atmosphere and sealed with a septum. The wavelength of maximum absorption $\left(\lambda_{\max }\right)$ was recorded at room temperature using a UV-visible spectrophotometer. Different polarity parameters were derived by employing the empirical equations given in Table 2 .

\section{Viscosity measurement}

The viscosities $(\eta)$ of different DES systems were measured at room temperature by using a Brookfield rotating viscometer (RVDV1) with a cone and plate arrangement. The viscosity $(\eta)$ values of DESs were obtained according to the given equation:

$$
\eta=(100 / \mathrm{RPM})(\mathrm{TK})(\text { torque })(\mathrm{SMC})
$$

where, TK (0.09373), RPM and SMC (0.327) are the viscometer torque constant, speed and spindle multiplier constant, respectively.

\section{$\mathrm{CO}_{2}$ absorption experiment}

In the present study, $\mathrm{CO}_{2}$ absorption measurements were carried out by bubbling $\mathrm{CO}_{2}$ gas, with a flow rate of $50 \mathrm{ml} \mathrm{min}^{-1}$ into a vial containing $\sim 3 \mathrm{~g}$ of DESs. The vial was weighed at regular intervals to record the differential weight of absorbed $\mathrm{CO}_{2}$ and, consequently, the weight percent of absorbed $\mathrm{CO}_{2}$ in the respective DESs. The electronic balance used for weighing had an accuracy of $\pm 0.1 \mathrm{mg}$. Desorption experiments were also performed under inert atmosphere by weighing the vial at regular time intervals. The water content in DESs as measured by the Karl-Fisher Coulometer was $>30 \mathrm{ppm}$.

\section{Speciation of absorbed $\mathrm{CO}_{2}$ in carbamate, carbonate and bicarbonate}

The ${ }^{13} \mathrm{C}$ NMR spectroscopy was employed for the speciation of absorbed $\mathrm{CO}_{2}$ in DESs. Speciation of $\mathrm{CO}_{2}$ was based on the calibration of the ${ }^{13} \mathrm{C}$ NMR spectra of $\mathrm{CO}_{2}$-treated samples with those of the reference spectrum of $\mathrm{K}_{2} \mathrm{CO}_{3}$ and $\mathrm{KHCO}_{3}$, as shown by Mani et al. ${ }^{40}$ The ${ }^{13} \mathrm{C}$ NMR spectrum of $1 \mathrm{M} \mathrm{K}_{2} \mathrm{CO}_{3}$ and $\mathrm{KHCO}_{3}$ and the weighted mixture of two salts were prepared in $\mathrm{D}_{2} \mathrm{O}$. The speciation results of absorbed $\mathrm{CO}_{2}$ into carbamate, carbonate and bicarbonate were obtained based on the linear relation between the change of chemical shifts in $\mathrm{K}_{2} \mathrm{CO}_{3}$, $\mathrm{KHCO}_{3}$ and their mixtures against the molar compositions as shown in Fig. S1 (ESI $\dagger$ ). 


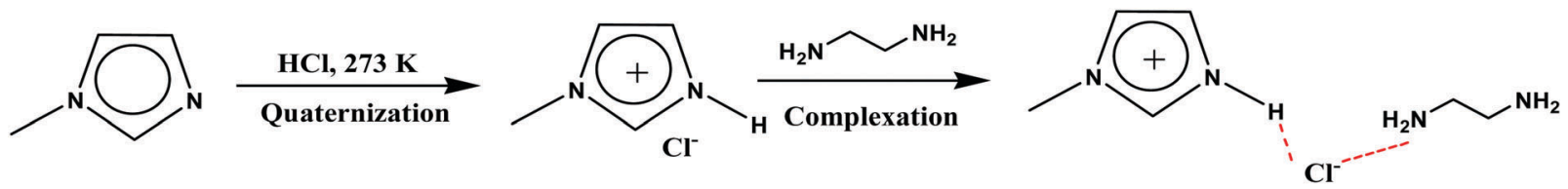

[HMIM.CI][EDA]

Scheme 1 Synthetic route to prepare a typical DES

Table 2 Empirical equation to determine the $E_{T}^{N}$ and Kamlet-Taft parameters

\begin{tabular}{|c|c|}
\hline Polarity parameters & Empirical equations \\
\hline $\begin{array}{l}\text { Electronic transition } \\
\text { energy }\left(E_{\mathrm{T}}^{\mathrm{N}}\right)\end{array}$ & $\begin{array}{l}E_{\mathrm{T}}(30)\left(\mathrm{kcal} \mathrm{mol}^{-1}\right)=h c \nu_{\max }^{\mathrm{abs}}=28591 / \lambda_{\max }^{\mathrm{abs}}(\mathrm{nm})=2.8591 \nu_{\max }^{\mathrm{abs}} \text { where } \nu_{\max }^{\mathrm{abs}} \text { is the maximum wavelength } \\
\text { of lowest energy band of Reichardt's dye }(1)\end{array}$ \\
\hline $\begin{array}{l}\text { Hydrogen bond donor } \\
\text { acidity }(\alpha)=\end{array}$ & $\frac{\left[E_{\mathrm{T}}(30)-14.6\left(\pi^{*}-0.23\right)-30.31\right]}{16.5}$ \\
\hline $\begin{array}{l}\text { Hydrogen bond acceptor } \\
\text { basicity }(\beta)=\end{array}$ & $\begin{array}{l}\frac{1.035 \nu_{(3) \max }-\nu_{(2) \max }+2.64}{2.8} \text { where } \nu_{(2) \max } \text { and } \nu_{(3) \max } \text { are the maximum wave number of the 4-nitroaniline } \\
\text { (probe 2) and } N, N \text {-diethyl-4-nitroaniline (probe 3), respectively in } \mathrm{kK} \text {, where } \mathrm{kK}=10^{3} \mathrm{~cm}^{-1}\end{array}$ \\
\hline
\end{tabular}

\section{Results and discussion}

For all DESs $\mathrm{CO}_{2}$ uptake experiments, viscosity and polarity measurements $\left(E_{\mathrm{T}}(30), \alpha, \beta\right.$ and $\left.\pi^{*}\right)$ were carried out at room temperature and values are presented in Table 3 . The $\mathrm{CO}_{2}$ uptake values for [MEA.Cl][EDA]-based DESs were observed to be in close agreement with those reported by Trivedi et al. ${ }^{32}$ The small deviation between current and reported values in the
$\mathrm{CO}_{2}$ uptake are owing to the difference in the experimental temperatures. ${ }^{32}$ All DESs exhibited the excellent $\mathrm{CO}_{2}$ uptake during the first hour whereas equilibrium was attained in 3-5 h, depending on affinity of the DESs towards $\mathrm{CO}_{2}$. For example, for [MEA.Cl][EDA] at $1: 3$ and $1: 4$ ratios, nearly $32.5 \mathrm{wt} \%$ and $34.1 \mathrm{wt} \%$ of $\mathrm{CO}_{2}$ was recorded in $1 \mathrm{~h}$, respectively. At equilibrium, these values improved to $36.5 \mathrm{wt} \%$ and $39 \mathrm{wt} \%$ for $1: 3$ and 1:4 mole ratios, respectively. Therefore, for comparison,

Table $3 \quad \mathrm{CO}_{2}$ uptake (molar and gravimetric) and polarity parameters in different DESs

\begin{tabular}{|c|c|c|c|c|c|c|c|c|}
\hline DESs & Mol. wt & $\mathrm{wt} \% \mathrm{CO}_{2}^{b}$ & Mole $\mathrm{CO}_{2} /$ mole DESs & $E_{\mathrm{T}} 30^{c} / \mathrm{kcal} \mathrm{mol}^{-1}$ & $\pi^{* c}$ & $\alpha^{c}$ & $\beta^{c}$ & $\eta^{d} / \mathrm{cP}$ \\
\hline$[\mathrm{MEA} \cdot \mathrm{Cl}][\mathrm{EDA}](1: 1)$ & 78.82 & $23.5(20.5)^{a}$ & 0.38 & 59.0 & 1.18 & 0.94 & 0.73 & 128.0 \\
\hline$[\mathrm{MEA} \cdot \mathrm{Cl}][\mathrm{EDA}](1: 2)$ & 72.58 & $30.9(24.4)^{a}$ & 0.47 & 55.8 & 1.17 & 0.76 & 0.80 & 17.3 \\
\hline$[\mathrm{MEA} \cdot \mathrm{Cl}][\mathrm{EDA}](1: 3)$ & 69.46 & $36.5(31.5)^{a}$ & 0.54 & 54.0 & 1.15 & 0.65 & 0.82 & 9.6 \\
\hline$[\mathrm{MEA} \cdot \mathrm{Cl}][\mathrm{EDA}](1: 4)$ & 67.59 & $39.0(30.8)^{a}$ & 0.57 & 52.7 & 1.13 & 0.57 & 0.86 & 7.0 \\
\hline$[\mathrm{MEA} \cdot \mathrm{Cl}][\mathrm{DETA}](1: 4)$ & 102.00 & 25.5 & 0.57 & 51.3 & 1.06 & 0.54 & 0.90 & 19.2 \\
\hline$[\mathrm{MEA} \cdot \mathrm{Cl}][\mathrm{TEPA}](1: 4)$ & 136.50 & 16.6 & 0.63 & 50.4 & 1.00 & 0.52 & 0.87 & 109.4 \\
\hline$[\mathrm{MEA} \cdot \mathrm{Cl}][\mathrm{PEHA}](1: 4)$ & 205.40 & 12.7 & 0.59 & 50.2 & 0.83 & 0.63 & 1.03 & 222.0 \\
\hline$[\mathrm{HMIM} \cdot \mathrm{Cl}][\mathrm{EDA}](1: 1)$ & 89.33 & 9.0 & 0.19 & - & - & - & - & 80.0 \\
\hline$[\mathrm{HMIM} \cdot \mathrm{Cl}][\mathrm{EDA}](1: 2)$ & 79.59 & 25.0 & 0.45 & 53.7 & 1.11 & 0.66 & 0.77 & 14.1 \\
\hline$[\mathrm{HMIM} \cdot \mathrm{Cl}][\mathrm{EDA}](1: 3)$ & 74.72 & 26.7 & 0.45 & 52.8 & 1.13 & 0.58 & 0.56 & 7.7 \\
\hline$[\mathrm{HMIM} \cdot \mathrm{Cl}][\mathrm{EDA}](1: 4)$ & 71.80 & 30.8 & 0.50 & 52.4 & 1.13 & 0.56 & 0.86 & 5.8 \\
\hline$[\mathrm{HMIM} \cdot \mathrm{Cl}][\mathrm{DETA}](1: 4)$ & 106.25 & 22.8 & 0.55 & 51.3 & 1.08 & 0.53 & 0.90 & 17.3 \\
\hline$[\mathrm{HMIM} \cdot \mathrm{Cl}][\mathrm{TEPA}](1: 4)$ & 175.15 & 9.9 & 0.39 & 50.3 & 0.98 & 0.53 & 0.92 & 100.5 \\
\hline [HMIM·Cl $][\mathrm{PEHA}](1: 4)$ & 209.61 & 8.4 & 0.40 & 49.9 & 0.91 & 0.55 & 0.94 & 213.0 \\
\hline$[\mathrm{MEA} \cdot \mathrm{Cl}][\mathrm{AP}](1: 1)$ & 86.33 & 15.8 & 0.28 & 59.7 & 1.15 & 1.02 & 0.58 & 126.7 \\
\hline$[\mathrm{MEA} \cdot \mathrm{Cl}][\mathrm{AP}](1: 2)$ & 82.56 & 21.0 & 0.37 & 58.0 & 1.13 & 0.92 & 0.68 & 67.0 \\
\hline$[\mathrm{MEA} \cdot \mathrm{Cl}][\mathrm{AP}](1: 3)$ & 80.72 & 24.3 & 0.42 & 57.2 & 1.09 & 0.89 & 0.74 & 64.0 \\
\hline$[\mathrm{MEA} \cdot \mathrm{Cl}][\mathrm{AP}](1: 4)$ & 79.60 & 26.3 & 0.46 & 56.6 & 1.07 & 0.87 & 0.74 & 55.0 \\
\hline$[\mathrm{HMIM} \cdot \mathrm{Cl}][\mathrm{AP}](1: 1)$ & 96.84 & 2.0 & 0.04 & 59.2 & 1.11 & 1.01 & 0.65 & 130.6 \\
\hline$[\mathrm{HMIM} \cdot \mathrm{Cl}][\mathrm{AP}](1: 2)$ & 89.59 & 9.5 & 0.21 & 58.0 & 1.11 & 0.93 & 0.67 & 57.0 \\
\hline$[\mathrm{HMIM} \cdot \mathrm{Cl}][\mathrm{AP}](1: 3)$ & 85.97 & 13.9 & 0.30 & 57.2 & 1.11 & 0.88 & 0.76 & 49.9 \\
\hline$[\mathrm{HMIM} \cdot \mathrm{Cl}][\mathrm{AP}](1: 4)$ & 83.8 & 19.4 & 0.37 & 56.7 & 1.08 & 0.88 & 0.72 & 39.0 \\
\hline$[\mathrm{TBAB}][\mathrm{AP}](1: 2)$ & 157.53 & 11.1 & 0.43 & 47.3 & 1.08 & 0.27 & 0.88 & 243.0 \\
\hline$[\mathrm{TBAB}][\mathrm{AP}](1: 3)$ & 136.93 & 15.6 & 0.49 & 48.1 & 1.08 & 0.32 & 0.85 & 51.2 \\
\hline$[\mathrm{TBAB}][\mathrm{AP}](1: 4)$ & 124.56 & 18.1 & 0.51 & 48.5 & 1.02 & 0.39 & 0.90 & 38.4 \\
\hline$[\mathrm{TBAB}][\mathrm{AMP}](1: 3)$ & 147.45 & 10.5 & 0.35 & 48.9 & 0.99 & 0.43 & 0.94 & 199.7 \\
\hline$[\mathrm{TBAB}][\mathrm{AMP}](1: 4)$ & 135.79 & 12.2 & 0.38 & 49.2 & 0.98 & 0.46 & 0.89 & 252.2 \\
\hline
\end{tabular}

${ }^{a}$ Ref. $32 .{ }^{b}$ Error associated with wt $\% \mathrm{CO}_{2}$ is $\leq \pm 0.004 .{ }^{c}$ Polarity values are reproducible within $\pm 0.004 .{ }^{d}$ Viscosity values are reproducible within precision of \pm 0.003 . 
$\mathrm{CO}_{2}$ uptake measured during the first hour in DESs is used in all graphical representations whereas the equilibrium $\mathrm{CO}_{2} \mathrm{wt} \%$ are given in Table 3.

$\mathrm{CO}_{2}$ capture in DESs can be improved (1) by optimization i.e. by varying the molar ratio of HBD component and (2) by altering the strength of HBD and HBA components. Optimization experiments are carried out for [MEA.Cl][EDA]-, [HMIM.Cl][EDA]-, [MEA.Cl][AP], [HMIM-Cl][AP], [TBAB][AP]- and [TBAB][AMP]-based DESs while the influence of various HBA and HBD components on $\mathrm{CO}_{2}$ uptake is examined for the DESs prepared by mixing [MEA.Cl] and [HMIM.Cl] with [EDA], [DETA], [TEPA] and [PEHA] at $1: 4$ mole ratio. Compared to [MEA.Cl]- (m.p. $\left.72{ }^{\circ} \mathrm{C}\right)$ and [HMIM.Cl] (m.p. $75^{\circ} \mathrm{C}$ ) which formed DES even at $1: 1$ mole ratio with HBDs, [TBAB] (m.p. $103{ }^{\circ} \mathrm{C}$ ) formed DES at higher mole ratio with $[\mathrm{AP}](1: 2)$ and $[\mathrm{AMP}](1: 3)$ due to high melting point.

\section{Effect of molar ratio of $\mathrm{HBD}$ on $\mathrm{CO}_{2}$ capture}

In case of [MEA.Cl][EDA]-, [HMIM.Cl][EDA]-, [MEA.Cl][AP]-, [HMIM.Cl][AP]-, [TBAB][AP]-, and [TBAB][AMP]-based DESs, $\mathrm{CO}_{2}$ uptake was observed to improve with the increasing mole ratio of HBD components (i.e. optimization) as shown in Table 3. The $\mathrm{CO}_{2}$ uptake in [MEA.Cl][EDA]-class of DESs was increased by $\sim 6 \%$ from $1: 1$ to $1: 3$, whereas only $3 \%$ increment was observed at 1:4 ratio (Fig. 2(a)). The lower increment in $\mathrm{CO}_{2}$ uptake at 1:4 indicates dissipation of the capability of the [MEA.Cl][EDA]-based DESs formed beyond 1:4 mole ratio. Therefore, $\mathrm{CO}_{2}$ uptake in DESs prepared beyond 1:4 was not considered. However, in case of [MEA.Cl][EDA], an increase in the $\mathrm{CO}_{2}$ uptake from $23.5 \mathrm{wt} \%$ to $39 \mathrm{wt} \%$ was less than two-folds despite increasing the [EDA] ratio by four-folds; this clearly indicates the role of intermolecular interactions upon $\mathrm{CO}_{2}$ absorption and reflects in terms of polarity parameters ( $\alpha$ and $\beta$ values).

Compared to the [MEA.Cl][EDA]-based DESs, [HMIM.Cl][EDA]class of DESs exhibited lower $\mathrm{CO}_{2}$ uptake during optimization from 1:1 to $1: 4$ with identical HBD component (Fig. 2(b)). The lower $\mathrm{CO}_{2}$ uptake in [HMIM-Cl][EDA] than [MEA.Cl][EDA] can be attributed to the strong $\mathrm{H}$-bonding interactions between former than later. [HMIM.Cl] contains more acidic protons than [MEA.Cl] and therefore coordinates strongly with [EDA] at all mole ratios and brings early dissipation upon $\mathrm{CO}_{2}$ uptake. In [MEA.Cl][AP]based DESs $\mathrm{CO}_{2}$ uptake was found to increase with the mole ratio of [AP] from $1: 1$ to $1: 2$ but decreased beyond 1:2 (Fig. 2(c)). Surprisingly, in case of the [HMIM-Cl][AP]-based DESs, a significant improvement in the $\mathrm{CO}_{2}$ uptake was observed upon increasing [AP] at all mole ratios (Fig. 2(d)). The lower bonding aptitude of [MEA.Cl] towards HBDs makes it efficient HBA than [HMIM.Cl] and [TBAB]. The higher $\mathrm{CO}_{2}$ uptake in [MEA.Cl] $[\mathrm{AP}]=$ $1: 1$ than [HMIM.Cl][EDA] $=1: 1$ despite the lower basicity of [AP] than [EDA] also confirms the potential of [MEA.Cl] in $\mathrm{CO}_{2}$ absorption. Beyond 1:1, [HMIM.Cl][EDA] surpassed [MEA.Cl][AP] in $\mathrm{CO}_{2}$ uptake because of the increased basicity.

The TBAB-based DESs demonstrated a significant improvement in the $\mathrm{CO}_{2}$ uptake upon optimization (Fig. S2(a), ESI $\dagger$ ). Surprisingly, the $\mathrm{CO}_{2}$ absorption kinetics in case of [TBAB][AMP], at a molar ratio of $1: 3$, was faster than that at $1: 4$ in the initial phase but improved later and went through a crossover point (Fig. S2(b), ESI $\dagger$ ).
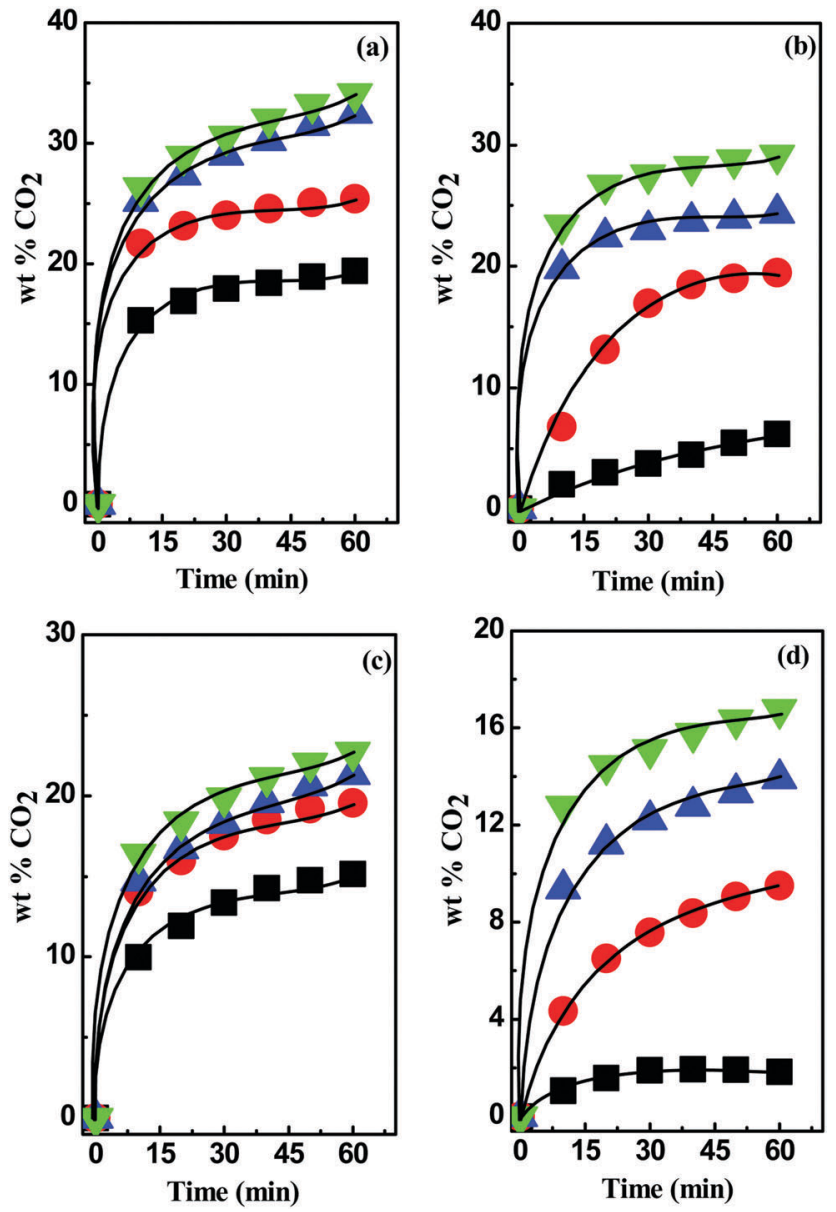

Fig. $2 \mathrm{CO}_{2}$ uptake kinetics in (a) [MEA.Cl][EDA]-, (b) [HMIM.Cl][EDA]-, (c) [MEA.CI][AP]-, and (d) [HMIM.Cl][AP]-based DESs at 1:1 (ם), 1:2 (O), $1: 3(\Delta)$ and $1: 4(\nabla)$ molar ratios.

This abnormal change in the behavior of [TBAB][AMP]-based DESs might be caused by the changes in viscosity. The $\mathrm{CO}_{2}$ uptake kinetics in DESs at 1:4 mole ratios are following the order:

$$
\begin{gathered}
{[\mathrm{MEA} \cdot \mathrm{Cl}][\mathrm{EDA}]>[\mathrm{HMIM} \cdot \mathrm{Cl}][\mathrm{EDA}]>[\mathrm{MEA} \cdot \mathrm{Cl}][\mathrm{AP}]>} \\
{[\mathrm{HMIM} \cdot \mathrm{Cl}][\mathrm{AP}]>[\mathrm{TBAB}][\mathrm{AP}]>[\mathrm{TBAB}][\mathrm{AMP}]}
\end{gathered}
$$

In-depth analysis of the $\mathrm{CO}_{2}$ uptake values in DESs in terms of the change in intermolecular interactions is presented by employing the $E_{\mathrm{T}}(30)$ and Kamlet-Taft parameters $\left(\alpha, \beta\right.$ and $\left.\pi^{*}\right)$. For [MEA.Cl] [EDA]-based DESs an inverse relation $\left(r^{2}=0.99325\right)$ between $E_{\mathrm{T}}(30)$ values and $\mathrm{CO}_{2}$ wt\% was obtained (Fig. 3(a)) suggesting involvement of non-polar interactions during $\mathrm{CO}_{2}$ capture. The polarity index value $\pi^{*}$, which reflects the electrolytic strength of a medium, was found decreasing during optimization in [MEA.Cl][EDA] (Fig. 3(b)). The polarity $\left(E_{\mathrm{T}}(30)\right)$ of a medium depends on the relative magnitude of $\alpha$ and $\beta$. In general, the polarity of a medium decreases with the increasing value of $\beta$ over $\alpha$ and vice versa. ${ }^{41}$ During the optimization of the [MEA.Cl][EDA] system, $\beta$ successively increases over $\alpha$ as shown in Fig. 3(c). A positive $\beta$ - $\alpha$ values for [MEA.Cl][EDA]-based DESs at $1: 2,1: 3$ and $1: 4$ indicate basic nature of DESs. Thus, 

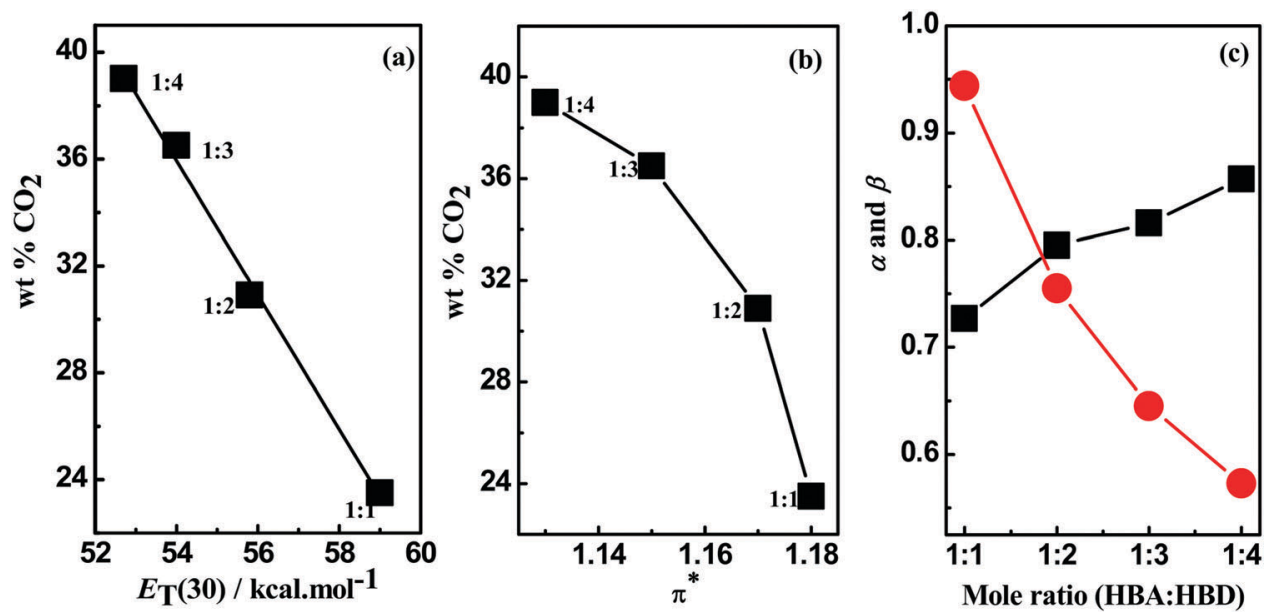

Fig. 3 Effect of polarity (a) $\left(E_{\mathrm{T}}(30)\right)$ and (b) $\pi^{*}$ on $\mathrm{CO}_{2}$ uptake and variation of (c) $\alpha(\mathrm{O})$ and $\beta$

$\mathrm{CO}_{2}$ capture in [MEA.Cl][EDA]-based DESs is guided by the screened basicity.

The [HMIM.Cl][EDA]-based DESs also exhibited the inverse relation between $E_{\mathrm{T}}(30)$ and $\mathrm{CO}_{2}$ uptake during optimization. Unfortunately, the polarity of the [HMIM.Cl][EDA] could not be measured at $1: 1$ as the DES turned solid upon addition of the dye. During optimization in [HMIM.Cl][EDA], $\beta$ was noted to guide the course of $\mathrm{CO}_{2}$ capture as suggested by the relative $\beta-\alpha$ values from $1: 2$ to $1: 4$. A decrease in the $E_{\mathrm{T}}(30)$ value is, however, not supported by a decrease in the $\pi^{*}$ as was the case with other classes of DESs. The opposite trend observed for $E_{\mathrm{T}}(30)$ and $\pi^{*}$ might arise from the higher electrolytic dissociation of [HMIM-Cl][EDA] upon increasing mole ratios of [EDA].

The [MEA.Cl][AP]-based DESs possessed higher $E_{\mathrm{T}}(30)$ than [MEA.Cl][EDA]-class of DESs because of the acidic proton $(-\mathrm{OH})$ of $[\mathrm{AP}]$. In spite of low basicity ( $\beta$ ), the [MEA.Cl][AP]-based DESs showed high $\mathrm{CO}_{2}$ uptake capacity which indicates that the system acidity $(\alpha)$ plays a crucial role in $\mathrm{CO}_{2}$ capture. In [AP], the $-\mathrm{OH}$ group at $\alpha$-position to the $-\mathrm{NH}_{2}$ seems stabilizing $\mathrm{CO}_{2}$ at the carbamic acid state and, thus facilitate $\mathrm{CO}_{2}$ absorption in DESs. A pictorial representation of the involvement of intermolecular interactions in the $\mathrm{CO}_{2}$ uptake is shown as Scheme 2. Similar behavior was observed in ILs where an acidic group $(-\mathrm{OH},-\mathrm{COOH})$ in the close vicinity of the amine is attributed for the multi-molar $\mathrm{CO}_{2}$ absorption. ${ }^{42}$ In case of [MEA.Cl][AP], a decreasing trend in $\pi^{*}$ upon optimization was similar as in case of $E_{\mathrm{T}}(30)$.
Unlike [MEA.Cl][AP]-class of DESs, [HMIM.Cl][AP]-based DESs possess lower $\mathrm{CO}_{2}$ uptake capacity further hinting to the stronger interaction in the [HMIM.Cl][AP]. The inferior $\mathrm{CO}_{2}$ uptake in [HMIM.Cl][AP] in comparison to [MEA.Cl][AP] arises due to the high $\beta$ values for comparable $\alpha$ values. It seems that higher $\beta$ values results in the closer vicinity of HBD to HBA and thus lower polarity and decelerate $\mathrm{CO}_{2}$ uptake. Similar conclusions were drawn by Welton et al. during the kinetic study of Diels-Alder reaction in ILs. ${ }^{43}$ All [TBAB][AP]- and [TBAB][AMP]-based DESs are prepared from aprotic HBA ([TBAB]) thus possess lower $E_{\mathrm{T}}(30)$ and consequently showed moderate $\mathrm{CO}_{2}$ uptake. Small increase in the $\mathrm{CO}_{2}$ uptake during optimization of the [TBAB][AP]- and [TBAB][AMP]-based DESs is thus due to the acidic-stabilization of $\mathrm{CO}_{2}$ as proposed in case of [MEA.Cl][AP]. This notion is further supported by increasing $\alpha$ value upon optimization.

Based on the above correlation it can be inferred that the $\mathrm{CO}_{2}$ uptake in DESs does not solely depend on the basicity of the HBD component but principally on the strength of the intermolecular H-bonding interactions between the HBD and HBA components as suggested by the equilibrium between $\alpha$ and $\beta$ values. Higher $\mathrm{CO}_{2}$ uptake in all classes of DESs is also favored by a drop in the viscosity $(\eta)$ during optimization. At lower viscosity, the $\mathrm{CO}_{2}$ molecules diffuse faster in the DES continuum and therefore, improves the probability of chemisorption. It is noted that a large difference in the $\alpha$ and $\beta$ values
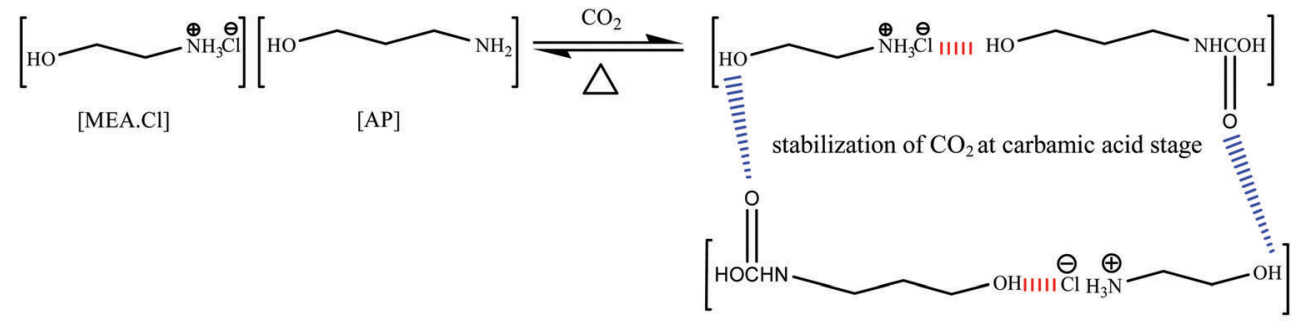

stabilized carbamic acid via $\mathrm{H}$-bonding

Scheme 2 Pictorial representation of involvement of intermolecular interaction in $\mathrm{CO}_{2}$ capture. 
results in multi-center bonding and hence, result in high viscosity whereas small differences counter-act such interactions and result in lower viscosity and high $\mathrm{CO}_{2}$ absorption.
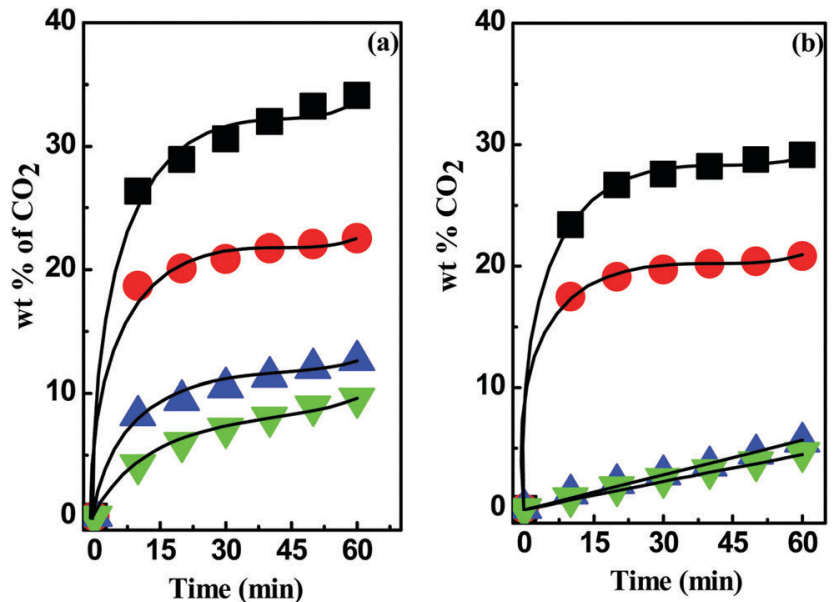

Fig. $4 \mathrm{CO}_{2}$ absorption kinetics in (a) [MEA.Cl]- and (b) [HMIM.Cl]-based DESs with hydrogen bond donor EDA $(\boldsymbol{\square}), \operatorname{DETA}(\boldsymbol{O}), \operatorname{TEPA}(\boldsymbol{\Lambda})$ and PEHA $(\nabla)$ at $1: 4$ mole ratio.

\section{Effect of $\mathrm{HBD}$ on $\mathrm{CO}_{2}$ uptake}

To investigate the role of $\mathrm{HBD}$ components on the $\mathrm{CO}_{2}$ uptake [EDA], [DETA], [TEPA] and [PEHA] were complexed with potential HBAs like, [MEA.Cl] and [HMIM.Cl] at $1: 4$. As shown in Fig. 4, $\mathrm{CO}_{2}$ uptake in both [MEA.Cl]- and [HMIM.Cl]-based DESs was noted to decrease with the increasing number of imine $(-\mathrm{NH})$ groups in the HBD components. The comparison demonstrated that among both classes, [MEA.Cl][EDA] and [HMIM.Cl][EDA] were the most efficient DES while [MEA.Cl][PEHA] and [HMIM.Cl] [PEHA] had the lowest capacity in terms of the $\mathrm{CO}_{2}$ capture, despite the higher basicity of [PEHA] $(\beta=1.027)$ than [EDA] $(\beta=0.857)$. The drop in the $\mathrm{CO}_{2}$ uptake capacity of [PEHA]containing DESs than [EDA]-based DESs might arise due to the higher viscosity of former than later. The high viscosity retards the diffusion of $\mathrm{CO}_{2}$ molecules towards the active sites and, consequently, impede the rapid $\mathrm{CO}_{2}$ uptake (Fig. S3, ESI $\dagger$ ).

\section{Effect of $\mathrm{HBA}$ on $\mathrm{CO}_{2}$ capture}

Similar to HBDs, the acidity of the HBA components also affects the $\mathrm{CO}_{2}$ uptake significantly. It is evident from Fig. 5 that [MEA.Cl] and [HMIM.Cl] impose strong control over the $\mathrm{CO}_{2}$
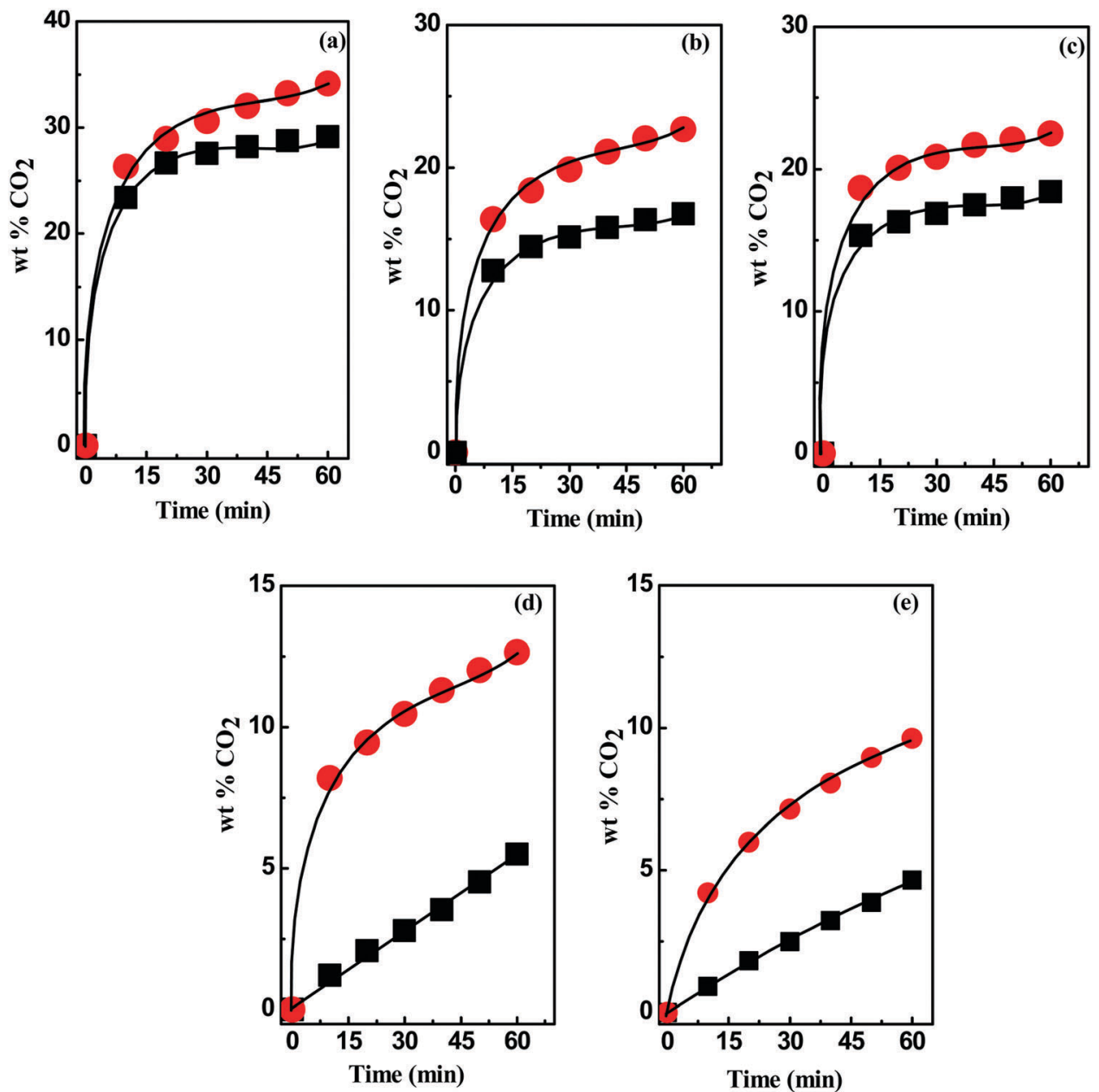

Fig. $5 \mathrm{CO}_{2}$ absorption kinetics in [MEA.Cl]- $(\bigcirc)$ and [HMIM.Cl]-based (

DESs with (a) EDA, (b) AP (c) DETA, (d) TEPA and (e) PEHA at 1:4 mole ratio. 
uptake process when complexed with [TEPA] and [PEHA] whereas, a small difference was observed with [EDA], [DETA] and $[\mathrm{AP}]$, at 1:4 mole ratio. However, in all cases [MEA.Cl]based DESs showed higher potential in $\mathrm{CO}_{2}$ capture than the [HMIM.Cl]-based DESs. The higher aptitude of [MEA.Cl]-based DESs can be accounted to the nature of chemical environment which in turn depend on $\alpha-\beta$ values. The relative $\alpha-\beta$ difference is comparatively lower for [MEA.Cl]-based DESs than [HMIM.Cl]class of DESs. Similar conclusions were drawn by Sharmad et al. and Yuan et al. during $\mathrm{CO}_{2}$ absorption in DESs and in aqueous piperazine/2-methylpiperazine, respectively. ${ }^{4,45}$ In general, if $\alpha$ has an edge over $\beta$, it gives acidic or polar characteristic to the active site, whereas in reverse scenario a stable chemical environment is formed for the $\mathrm{CO}_{2}$ capture due to the abundance of the apolar sites in the medium. Therefore, smaller differences in the $\alpha-\beta$ value indicate the prevalence of stable interacting sites in DES for $\mathrm{CO}_{2}$ stabilization. This view is further supported by the viscosity data as [MEA.Cl]-based DESs have higher $\mathrm{CO}_{2}$ uptake than [HMIM.Cl]-class of DESs despite their higher viscosities. Thus, the most proficient DES possess nearly similar $\alpha$ and $\beta$ values. The equilibration between donor and acceptor sites lowers polarity and thereby increase non-directional forces in the $\mathrm{CO}_{2}$ capture.

\section{Speciation of absorbed $\mathrm{CO}_{2}$ in DESs}

$\mathrm{CO}_{2}$ absorption in different DESs was also monitored by recording the FT-IR and ${ }^{1} \mathrm{H}$ - and ${ }^{13} \mathrm{C}-\mathrm{NMR}$ spectra before and after the experiments. FTIR spectra of DESs showed a broad peak at $\sim 2900 \mathrm{~cm}^{-1}$ due to N-H-mediated H-bonding (Fig. S4, ESI $\dagger$ ). The presence of carbamate species was revealed by the absorption bands at $\sim 1559,1293$ and $851 \mathrm{~cm}^{-1}$, respectively, owing to the asymmetric, symmetric and bending vibrations. In [AP]-based DESs, the additional absorption band at $\sim 1350-1500 \mathrm{~cm}^{-1}$ indicates the presence of $\mathrm{HCO}_{3}{ }^{-} / \mathrm{CO}_{3}{ }^{2-}$. The enhanced peaks at $\sim 1098$ and $1190 \mathrm{~cm}^{-1}$ correspond to the stretching modes of $\mathrm{C}-\mathrm{N}$ and $\mathrm{C}-\mathrm{O}$ groups, respectively, and fortify $\mathrm{CO}_{2}$ absorption.
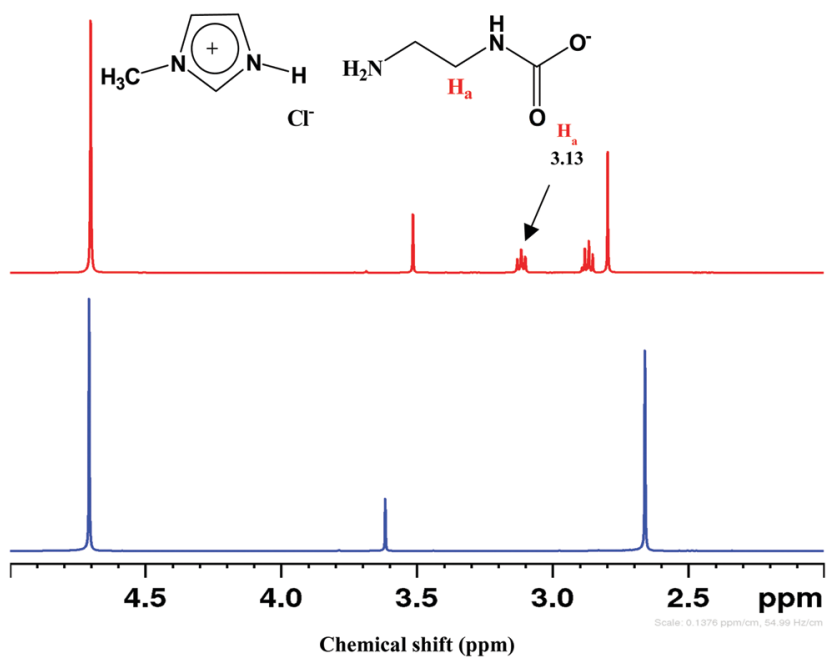

Fig. $6{ }^{1} \mathrm{H}$ NMR spectra of [HMIM.CI][EDA] at 1:4 before (lower) and after (upper) $\mathrm{CO}_{2}$ uptake.
$\mathrm{CO}_{2}$ uptake in solvent results in carbamate $\left(\mathrm{NH}_{2} \mathrm{COO}^{-}\right)$, carbonate $\left(\mathrm{CO}_{3}{ }^{2-}\right)$ and bicarbonate $\left(\mathrm{HCO}_{3}{ }^{-}\right)$depending on the strength of basicity and acidity. Under the acidic condition, $\mathrm{NH}_{2} \mathrm{COO}^{-}$hydrolyzes to $\mathrm{CO}_{3}{ }^{2-} / \mathrm{HCO}_{3}{ }^{-} \cdot{ }^{46,47}$ The ${ }^{1} \mathrm{H}$ NMR spectrum of $\mathrm{CO}_{2}$ treated DESs show carbamate peak at $3.13 \mathrm{ppm}$, along with the downfield shifting of other peaks due to the conversion of $-\mathrm{NH}_{2}$ to $-\mathrm{NH}$ (Fig. 6). On ${ }^{13} \mathrm{C} \mathrm{NMR}$ scale, $\mathrm{NH}_{2} \mathrm{COO}^{-}$appears at $>164$ ppm whereas $\mathrm{CO}_{3}{ }^{2-} / \mathrm{HCO}_{3}{ }^{-}$resonate below $162 \mathrm{ppm}$ as exhibited in Fig. 7. The fast equilibration of a proton between $\mathrm{HCO}_{3}{ }^{-}$and $\mathrm{CO}_{3}{ }^{2-}$ results in a single peak in ${ }^{13} \mathrm{C}$ NMR whose chemical shifts depend on the relative concentration of the carbonate and bicarbonate species.

The ${ }^{13} \mathrm{C}$ NMR spectrum of different $\mathrm{CO}_{2}$-absorbed DESs revealed the presence of $\mathrm{NH}_{2} \mathrm{COO}^{-}$and $\mathrm{CO}_{3}{ }^{2-} / \mathrm{HCO}_{3}{ }^{-}$. Both [MEA.Cl][EDA]- and [HMIM.Cl][EDA]-based DESs showed only $\mathrm{NH}_{2} \mathrm{COO}^{-}$signal upon $\mathrm{CO}_{2}$ bubbling (Fig. S5, ESI $\dagger$ ) because of

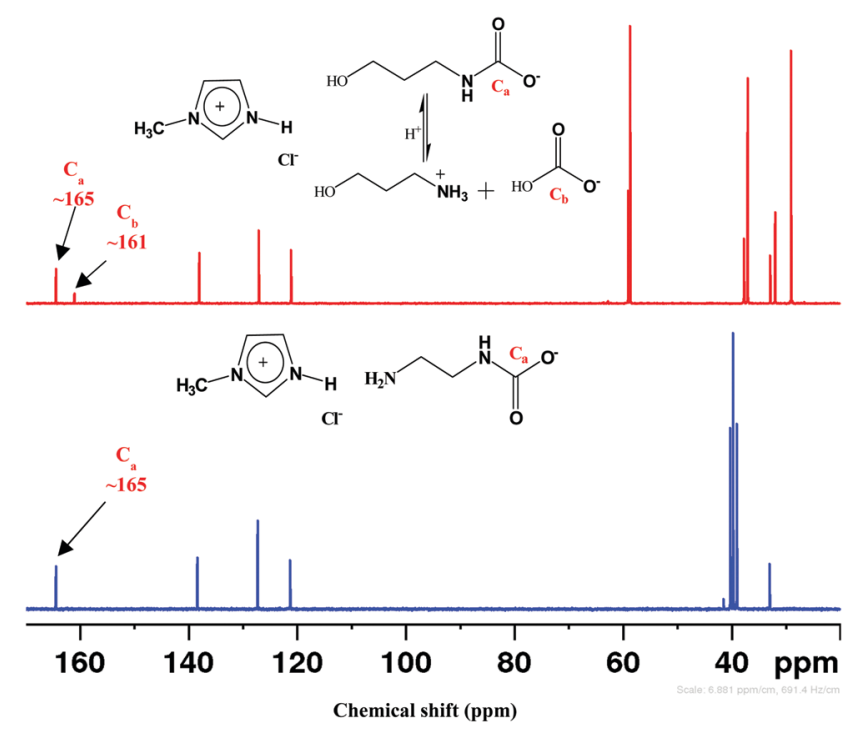

Fig. $7{ }^{13} \mathrm{C}$ NMR spectra of [HMIM.Cl][EDA] (lower) and [HMIM.CI][AP] (upper) at 1:4 after $\mathrm{CO}_{2}$ uptake.

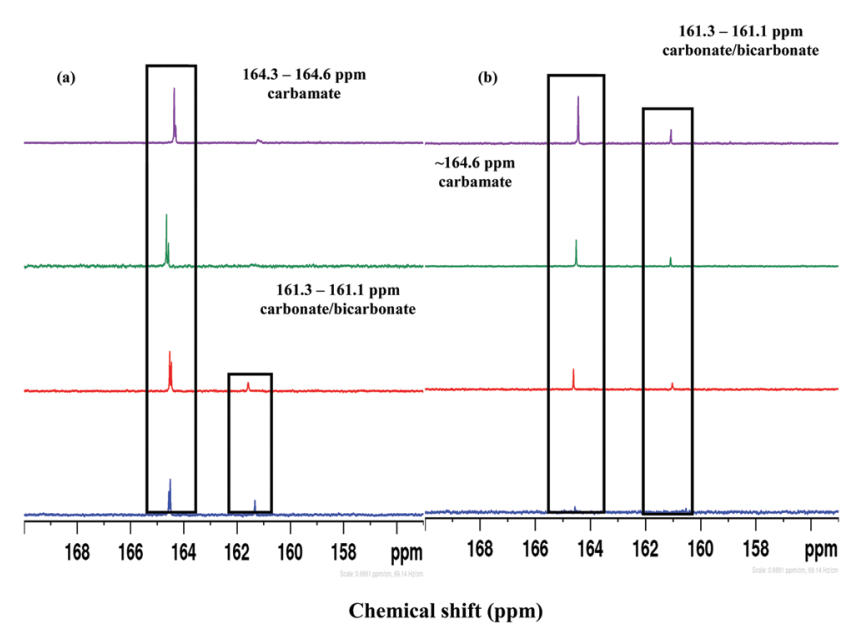

Fig. $8{ }^{13} \mathrm{C}$ NMR spectrum of (a) [MEA.Cl][AP]- and [HMIM.CI][AP]-based DESs at $1: 1(-), 1: 2(-), 1: 3(-)$ and $1: 4(-)$ mole ratios. 
high $\beta$ which grows further upon optimization (Table 3). In [MEA.Cl][AP]- and [HMIM.Cl][AP]-classes of DESs, $\mathrm{CO}_{3}{ }^{2-} / \mathrm{HCO}_{3}{ }^{-}$ peak appeared at $\sim 160-161$ ppm upon $\mathrm{CO}_{2}$ capture but with a different pattern of intensity change during optimization. For [MEA.Cl][AP]-class of DESs, $\mathrm{CO}_{3}{ }^{2-} / \mathrm{HCO}_{3}{ }^{-}$peak was noticed only at $1: 1$ and $1: 2$, whereas, in [HMIM.Cl][AP]-based DESs, $\mathrm{CO}_{3}{ }^{2-} / \mathrm{HCO}_{3}{ }^{-}$peak appeared at all mole ratios $(1: 1$ to $1: 4)$ as shown in Fig. 8. This unusual behavior of [MEA.Cl][AP]-class of
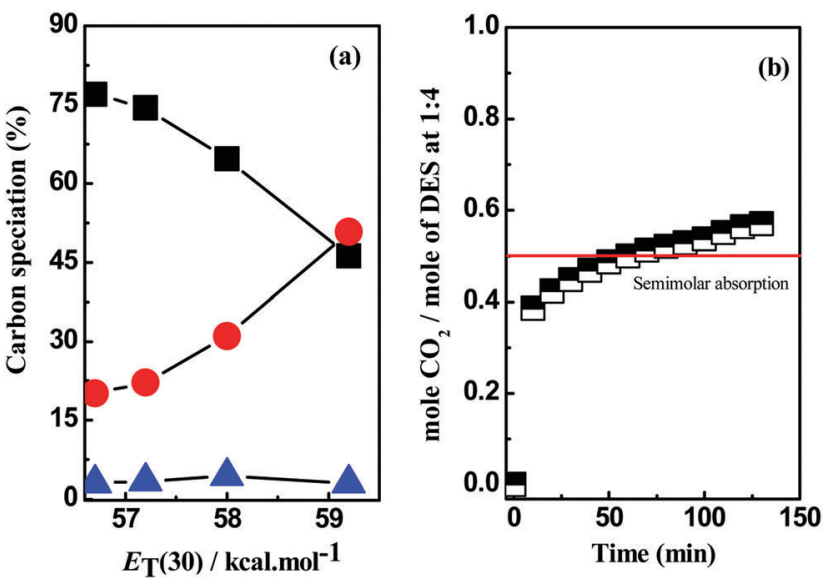

Fig. 9 (a) Speciation profiles of carbamate

bicarbonate carbonate (A) vs. $E_{T}(30)$ in $\mathrm{HMIM}$. Cl AP (1 : 4) and (b) molar $\mathrm{CO}_{2}$ uptake in a typical DES at 1:4 mole ratio.

Table 4 Speciation profiles of $\mathrm{CO}_{2}$ in different DESs

\begin{tabular}{|c|c|c|c|}
\hline DESs & $\begin{array}{l}\text { Mol\% } \% \\
\text { carbamate }^{a}\end{array}$ & $\begin{array}{l}\text { Mol\% } \\
\text { bicarbonate }^{a}\end{array}$ & $\begin{array}{l}\text { Mol\% } \% \\
\text { carbonate }^{a}\end{array}$ \\
\hline$[\mathrm{HMIM} \cdot \mathrm{Cl}][\mathrm{AP}](1: 1)$ & 46.2 & 50.8 & 3.0 \\
\hline$[\mathrm{HMIM} \cdot \mathrm{Cl}][\mathrm{AP}](1: 2)$ & 64.7 & 31 & 4.3 \\
\hline$[\mathrm{HMIM} \cdot \mathrm{Cl}][\mathrm{AP}](1: 3)$ & 74.4 & 22.2 & 3.4 \\
\hline$[\mathrm{HMIM} \cdot \mathrm{Cl}][\mathrm{AP}](1: 4)$ & 76.9 & 20.1 & 3.0 \\
\hline$[\mathrm{MEA} \cdot \mathrm{Cl}][\mathrm{AP}](1: 1)$ & 75.8 & 20.2 & 4.0 \\
\hline$[\mathrm{MEA} \cdot \mathrm{Cl}][\mathrm{AP}](1: 2)$ & 78.9 & 16.9 & 4.2 \\
\hline$[\mathrm{TBAB}][\mathrm{AP}](1: 3)$ & 66.9 & 27.6 & 5.5 \\
\hline$[\mathrm{TBAB}][\mathrm{AP}](1: 4)$ & 72.7 & 23.6 & 3.7 \\
\hline
\end{tabular}

${ }^{a}$ Error associated with mol\% of different species are $\leq \pm 0.003$.
DESs might arise because of the strong hydrogen bonding interaction between $\mathrm{Cl}^{-}$and -OH group in [AP] which strengthen upon optimization.

In [HMIM.Cl] $[\mathrm{AP}], \mathrm{Cl}^{-}$is weakly coordinated with $-\mathrm{OH}$ because of the strong interaction with acidic hydrogens on $[\mathrm{HMIM}]^{+}$cation. Further addition of $[\mathrm{AP}]$ acts as a "dilutant" for the interacting components $[\mathrm{HMIM} \cdot \mathrm{Cl}]$ and $[\mathrm{AP}]$ and therefore $[\mathrm{AP}]$ becomes more available in the super-crystalline lattice of DESs during optimization. This enables the $-\mathrm{OH}$ group of $[\mathrm{AP}]$ to participate in the hydrolysis of $\mathrm{NH}_{2} \mathrm{COO}^{-}$to $\mathrm{CO}_{3}{ }^{2-} / \mathrm{HCO}_{3}{ }^{-}$upon optimization. The distribution of different carbon species in [HMIM-Cl][AP]-based DESs and their dependence on polarity are shown in Fig. 9(a). The speciation outcome of $\mathrm{CO}_{2}$ in different DESs are enlisted in Table 4.

[TBAB][AP]-based DESs forms carbamate, carbonate, and bicarbonate during $\mathrm{CO}_{2}$ uptake at $1: 3$ and $1: 4$ mole ratios as shown in their ${ }^{13} \mathrm{C}$ NMR spectra (Fig. S6, ESI $\dagger$ ) whereas, [TBAB][AMP]-class of DESs form only carbamate upon $\mathrm{CO}_{2}$ bubbling as indicated by their corresponding ${ }^{13} \mathrm{C}$ NMR spectra (Fig. S7, ESI $\dagger$ ).

The molar uptake plot (Fig. 9(b)) suggest semimolar mechanism, where two moles of DES interacts one mole of $\mathrm{CO}_{2}(2: 1)$, was operative in all DESs as shown in Table 3. The semimolar $\mathrm{CO}_{2}$ uptake in DESs can be explained by the steps shown in Scheme 3.

\section{Effect of water}

With the aim of simulating $\mathrm{CO}_{2}$ uptake under more realistic conditions, uptake kinetics was measured by mixing water in DESs at $1: 4$. The inferior uptake kinetics was noted with the increasing wt\% of water in DES. These observations are in contradiction to the previous reports where improved $\mathrm{CO}_{2}$ uptake is reported due to the reduced intermolecular interactions in the presence of water. ${ }^{32}$ In contrast to the $39 \mathrm{wt} \%$ of $\mathrm{CO}_{2}$ by pure [MEA.Cl][EDA] at $1: 4,35.7 \mathrm{wt} \%, 35 \mathrm{wt} \%$ and $34.4 \mathrm{wt} \%$ of $\mathrm{CO}_{2}$ was obtained in [MEA.Cl][EDA] at $1: 4$ containing $10 \%, 20 \%$ and $30 \%$ of water, respectively (Fig. 10(a)). This deterioration in $\mathrm{CO}_{2}$ uptake entails that water competes with $\mathrm{CO}_{2}$ molecule for the active sites in DES. This contest increases

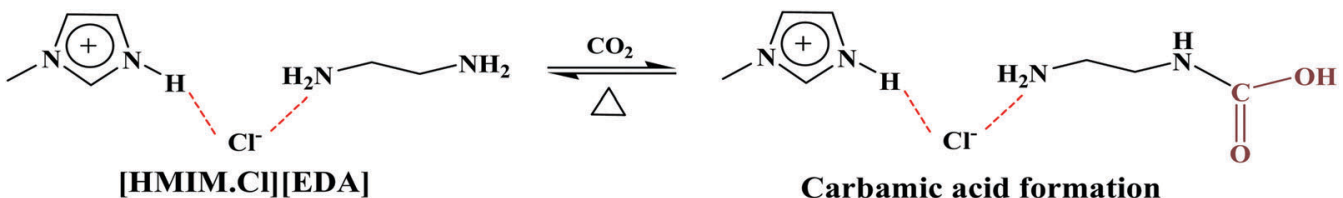

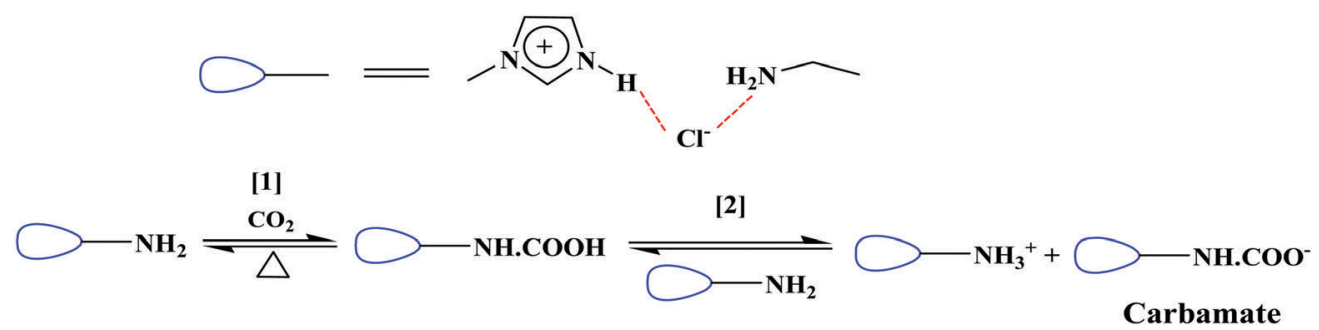

Scheme 3 A suggested mechanism of $\mathrm{CO}_{2}$ capture in DES based on molar uptake plot. 

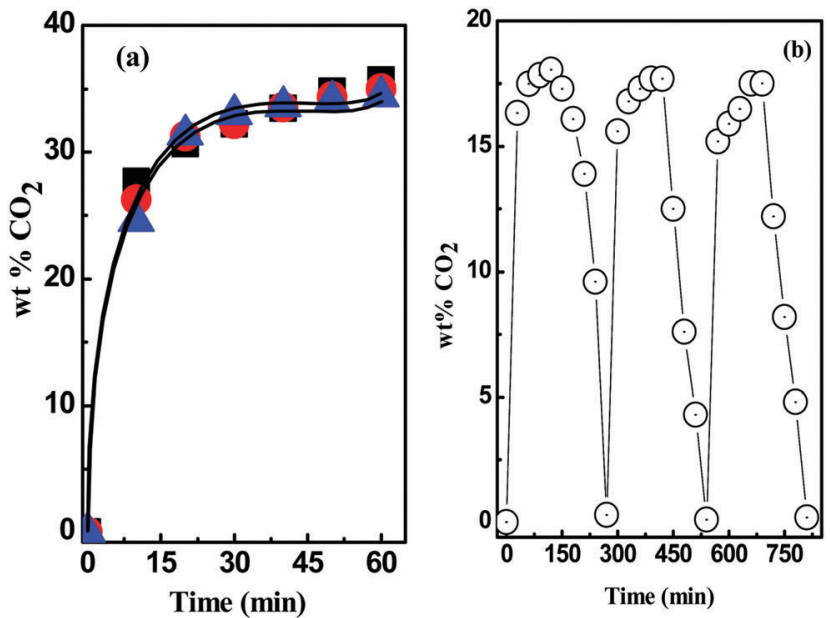

Fig. 10 (a) $\mathrm{CO}_{2}$ absorption kinetics in [MEA.Cl][EDA] at 1:4 + 10 wt\% (ש) $20 \mathrm{wt} \%(\mathbf{)})$ and $30 \mathrm{wt} \%(\boldsymbol{\Delta})$ water and (b) consecutive absorptiondesorption cycles of $30 \mathrm{wt} \%$ [MEA.CI][EDA] (1:4) in ethylene glycol. The absorption and desorption experiments were performed at room temperature and $70{ }^{\circ} \mathrm{C}$, respectively.

with wt\% of water and lowers $\mathrm{CO}_{2}$ uptake of aqueous DES. Goodrich et al. presented similar views during $\mathrm{CO}_{2}$ capture in an aqueous system. ${ }^{48}$ To comprehend the dependence of $\mathrm{CO}_{2}$ uptake on wt\% of $\mathrm{H}_{2} \mathrm{O}$ in DESs more clearly, we measured the polarity parameters and viscosity for [MEA.Cl][EDA] at $1: 4$ with 10,20 and $30 \mathrm{wt} \%$ of $\mathrm{H}_{2} \mathrm{O}$ and tabulated the results in Table 5 . Addition of $10 \mathrm{wt} \%$ water in [MEA.Cl][EDA] at $1: 4(\alpha=0.573$ and $\beta=0.857$ ) causes an increase in $\alpha$ to 0.632 while $\beta$ decreases to 0.815 . Similarly, the addition of $20 \mathrm{wt} \%$ and $30 \mathrm{wt} \%$ water in DES further results in lower $\beta$ values whereas $\alpha$ increase. The parallelism between $\mathrm{CO}_{2} \mathrm{wt} \%$ and $\beta$ in aqueous [MEA.Cl][EDA] at $1: 4$ thus overrules control of viscosity on $\mathrm{CO}_{2}$ uptake during dilution. The decrease in viscosity of aqueous DES should facilitate the $\mathrm{CO}_{2}$ uptake due to the ease of diffusion; however, the inferior $\mathrm{CO}_{2}$ kinetics observed upon dilution confirms the importance of $\beta$ in terms of $\mathrm{CO}_{2}$ capture in aqueous systems.

Table 5 Polarity parameters for aqueous [MEA.CI][EDA] at $1: 4$

\begin{tabular}{lllllll}
\hline Aqueous DESs & $\begin{array}{l}E_{\mathrm{T}}(30)^{a} / \\
\mathrm{kcal} \mathrm{mol}^{-1}\end{array}$ & $\pi^{* a}$ & $\alpha^{a}$ & $\beta^{a}$ & $\eta^{a} / \mathrm{cP}$ & $\begin{array}{l}\mathrm{wt}_{2} \\
\mathrm{CO}_{2}\end{array}$ \\
\hline $10 \mathrm{wt} \% \mathrm{H}_{2} \mathrm{O}+$ & 54.0 & 1.17 & 0.632 & 0.815 & 12.2 & 35.7 \\
{$[\mathrm{MEA} \cdot \mathrm{Cl}][\mathrm{EDA}](1: 4)$} & & & & & & \\
$20 \mathrm{wt} \% \mathrm{H}_{2} \mathrm{O}+$ & 55.4 & 1.22 & 0.688 & 0.731 & 9.6 & 35.0 \\
{$[\mathrm{MEA} \cdot \mathrm{Cl}][\mathrm{EDA}](1: 4)$} & & & & & & \\
$\begin{array}{l}30 \mathrm{wt} \% \mathrm{H}_{2} \mathrm{O}+ \\
{[\mathrm{MEA} \cdot \mathrm{Cl}][\mathrm{EDA}](1: 4)}\end{array}$ & 57.4 & 1.27 & 0.781 & 0.578 & 8.3 & 34.4 \\
${ }^{a}$ Polarity and viscosity values are reproducible within & \pm 0.004 & and \\
\pm 0.003 , respectively. & & & & & &
\end{tabular}

\section{Recyclability experiment}

The feasibility of recycling DESs was monitored by performing the sequential absorption-desorption cycles with [MEA.Cl][EDA] at 1: 4 (Fig. 10(b)). A $30 \mathrm{wt} \%$ of ethylene glycol in [MEA.Cl][EDA] is taken as a reference solution for recyclability test and the cut-off limit was set around $18 \mathrm{wt} \% . \mathrm{CO}_{2}$ desorption in each step was achieved by heating the solution at $70{ }^{\circ} \mathrm{C}$ for $2 \mathrm{~h}$ under inert environment until complete desorption. ${ }^{49,50}$ Contrary to the report where loss in mass of task-specific DES was noted, the initial mass of solvent was preserved after each desorption cycle in our study. ${ }^{30}$ The stability of the [MEA.Cl][EDA] post consecutive absorption-desorption cycles was verified by ${ }^{13} \mathrm{C}$ NMR analysis (Fig. S8, ESI $\dagger$ ). The recycling experiments are consistent with the other studies performed with ILs and DESs. ${ }^{51}$

\section{Conclusions}

In conclusion, $\mathrm{CO}_{2}$ uptake in potential DESs is observed to depend on the nature of HBD substituents and their mole ratio relative to the HBA. Both these changes reduce polarity and thereby affect the strength of intermolecular interactions and consequently regulate $\mathrm{CO}_{2}$ uptake. In the light of Kamlet-Taft parameters, it is observed that the $\mathrm{CO}_{2}$ uptake capacity of DESs does not depend solely on the basicity of the HBD but is rather controlled by the strength of the intermolecular interactions between the components. The strong H-bonds in DESs result in high viscosity because of the large difference between $\alpha$ and $\beta$ value of constituents. In the most effective DESs, HBA and HBD were found least associated by the $\mathrm{H}$-bonding as suggested by the equilibrating $\alpha$ and $\beta$ values. The dominating role of HBAs in $\mathrm{CO}_{2}$ capture comes into play only with strongly basic HBDs such as, [TEPA] and [PEHA]. The speciation of absorbed $\mathrm{CO}_{2}$ into the carbamate, carbonate, and bicarbonate was observed only in [AP]- and [AMP]-based DESs and it favored in DES with $\alpha$ value. Rest other DESs absorbed $\mathrm{CO}_{2}$ as carbamate following semi-molar mechanism as suggested by their ${ }^{13} \mathrm{C}$ NMR spectra. Addition of water decelerate $\mathrm{CO}_{2}$ uptake in DESs due to the increasing $\alpha$ and decreasing $\beta$. These observations are expected to open discussion about the enriched chemistry involved in establishing DESs as a strong and viable candidates for the $\mathrm{CO}_{2}$ capture.

\section{Conflicts of interest}

There are no conflicts to declare.

\section{Acknowledgements}

SKS is thankful to Dr Ajaikumar Samikannu for assisting in the instrumentation during $\mathrm{CO}_{2}$ measurement. We are thankful to the Wallenberg Wood Science Center (WWSC), Kempe Foundations, and Bio4energy programme. This work is also part of the activities of the Johan Gadolin Process Chemistry Centre at Åbo Akademi University.

\section{References}

1 G. T. Rochelle, Science, 2009, 325, 1652-1654.

2 J. D. Figueroa, T. Fout, S. Plasynski, H. McIlvried and R. D. Srivastava, Int. J. Greenhouse Gas Control, 2008, 2, 9-20. 
3 C.-H. Yu, C.-H. Huang and C.-S. Tan, Aerosol Air Qual. Res., 2012, 12, 745-769.

4 B. Thitakamol, A. Veawab and A. Aroonwilas, Int. J. Greenhouse Gas Control, 2007, 1, 318-342.

5 R. Shao and A. Stangeland, Amines Used in $\mathrm{CO}_{2}$ Capture Health and Environmental Impacts, The Bellona Foundation, Oslo, Norway, 2009.

6 S. Zeng, X. Zhang, L. Bai, X. Zhang, H. Wang, J. Wang, D. Bao, M. Li, X. Liu and S. Zhang, Chem. Rev., 2017, 117, 9625-9673.

7 L. A. Blanchard, D. Hancu, E. J. Beckman and J. F. Brennecke, Nature, 1999, 399, 28-29.

8 I. Niedermaier, M. Bahlmann, C. Papp, C. Kolbeck, W. Wei, S. K. Calderon, M. Grabau, P. S. Schulz, P. Wasserscheid, H. P. Steinruck and F. Maier, J. Am. Chem. Soc., 2014, 136, 436-441.

9 B. F. Goodrich, J. C. de la Fuente, B. E. Gurkan, D. J. Zadigian, E. A. Price, Y. Huang and J. F. Brennecke, Ind. Eng. Chem. Res., 2011, 50, 111-118.

10 B. E. Gurkan, J. C. de la Fuente, E. M. Mindrup, L. E. Ficke, B. F. Goodrich, E. A. Price, W. F. Schneider and J. F. Brennecke, J. Am. Chem. Soc., 2010, 132, 2116-2117.

11 Y. Q. Zhang, S. J. Zhang, X. M. Lu, Q. Zhou, W. Fan and X. P. Zhang, Chem. - Eur. J., 2009, 15, 3003-3011.

12 C. M. Wang, X. Y. Luo, H. M. Luo, D. E. Jiang, H. R. Li and S. Dai, Angew. Chem., Int. Ed., 2011, 50, 4918-4922.

13 C. M. Wang, H. M. Luo, D. E. Jiang, H. R. Li and S. Dai, Angew. Chem., Int. Ed., 2010, 49, 5978-5981.

14 C. M. Wang, H. M. Luo, X. Y. Luo, H. R. Li and S. Dai, Green Chem., 2010, 12, 2019-2023.

15 X. Y. Luo, Y. Guo, F. Ding, H. Q. Zhao, G. K. Cui, H. R. Li and C. M. Wang, Angew. Chem., Int. Ed., 2014, 53, 7053-7057.

16 E. D. Bates, R. D. Mayton, I. Ntai and J. H. Davis, J. Am. Chem. Soc., 2002, 124, 926-927.

17 S. Saravanamurugan, A. J. Kunov-Kruse, R. Fehrmann and A. Riisager, ChemSusChem, 2014, 7, 897-902.

18 J. Z. Zhang, C. Jia, H. F. Dong, J. Q. Wang, X. P. Zhang and S. J. Zhang, Ind. Eng. Chem. Res., 2013, 52, 5835-5841.

19 X. M. Liu, G. H. Zhou, S. J. Zhang and X. Q. Yao, Fluid Phase Equilib., 2009, 284, 44-49.

20 B. Gurkan, B. F. Goodrich, E. M. Mindrup, L. E. Ficke, M. Massel, S. Seo, T. P. Senftle, H. Wu, M. F. Glaser, J. K. Shah, E. J. Maginn, J. F. Brennecke and W. F. Schneider, J. Phys. Chem. Lett., 2010, 1, 3494-3499.

21 A. P. Abbott, G. Capper, D. L. Davies, H. L. Munro, R. K. Rasheed and V. Tambyrajah, Chem. Commun., 2001, 2010-2011.

22 A. P. Abbott, D. Boothby, G. Capper, D. L. Davies and R. K. Rasheed, J. Am. Chem. Soc., 2004, 126, 9142-9147.

23 D. Carriazo, M. C. Serrano, M. C. Gutierrez, M. L. Ferrer and F. del Monte, Chem. Soc. Rev., 2012, 41, 4996-5014.

24 Q. H. Zhang, K. D. Vigier, S. Royer and F. Jerome, Chem. Soc. Rev., 2012, 41, 7108-7146.

25 A. Zhu, T. Jiang, B. Han, J. Zhang, Y. Xie and X. Ma, Green Chem., 2007, 9, 169-172.

26 X. Li, M. Hou, B. Han, X. Wang and L. Zou, J. Chem. Eng. Data, 2008, 53, 548-550.
27 R. B. Leron, A. Caparanga and M. H. Li, J. Taiwan Inst. Chem. Eng., 2013, 44, 879-885.

28 R. B. Leron and M. H. Li, Thermochim. Acta, 2013, 551, 14-19.

29 M. Francisco, A. van den Bruinhorst, L. F. Zubeir, C. J. Peters and M. C. Kroon, Fluid Phase Equilib., 2013, 340, 77-84.

30 L. L. Sze, S. Pandey, S. Ravula, S. Pandey, H. Zhao, G. A. Baker and S. N. Baker, ACS Sustainable Chem. Eng., 2014, 2, 2117-2123.

31 N. R. Mirza, N. J. Nicholas, Y. W. Kathryn, K. A. Mumford, S. E. Kentish and G. W. Stevens, J. Chem. Eng. Data, 2015, 60, 3246-3252.

32 T. J. Trivedi, J. H. Lee, H. J. Lee, Y. K. Jeong and J. W. Choi, Green Chem., 2016, 18, 2834-2842.

33 C. Reichardt, Chem. Rev., 1994, 94, 2319-2358.

34 M. J. Kamlet, J. L. Abboud and R. W. Taft, J. Am. Chem. Soc., 1977, 99, 6027-6038.

35 M. J. Kamlet and R. W. Taft, J. Am. Chem. Soc., 1976, 98, 377-383.

36 R. W. Taft and M. J. Kamlet, J. Am. Chem. Soc., 1976, 98, 2886-2894.

37 L. Crowhurst, P. R. Mawdsley, J. M. Perez-Arlandis, P. A. Salter and T. Welton, Phys. Chem. Chem. Phys., 2003, 5, 2790-2794.

38 S. K. Shukla and A. Kumar, J. Phys. Chem. B, 2015, 119, 5537-5545.

39 C. Liu, L. Ma, F. Sha, X. Qiao and J. Zhang, J. Mol. Liq., 2017, 232, 130-138.

40 F. Mani, M. Peruzzini and P. Stoppioni, Green Chem., 2006, 8, 995-1000.

41 S. K. Shukla and A. Kumar, Phys. Chem. Chem. Phys., 2012, 14, 2754-2761.

42 F.-F. Chen, K. Huang, Y. Zhou, Z.-Q. Tian, X. Zhu, D.-J. Tao, D. Jiang and S. Dai, Angew. Chem., Int. Ed., 2016, 55, 7166-7170.

43 A. Aggarwal, N. L. Lancaster, A. R. Sethi and T. Welton, Green Chem., 2002, 4, 517-520.

44 S. Sarmad, Y. Xie, J.-P. Mikkola and X. Jia, New J. Chem., 2017, 41, 290-301.

45 Y. Yuan, B. Sherman and G. T. Rochelle, Energy Procedia, 2017, 114, 2103-2120.

46 J. Kothandaraman, A. Goeppert, M. Czaun, G. A. Olah and G. K. Surya Prakash, Green Chem., 2016, 18, 5831-5838.

47 Y. Matsuzaki, H. Yamada, F. A. Chowdhury, T. Higashii, S. Kazama and M. Onoda, Energy Procedia, 2013, 37, 400-406.

48 B. F. Goodrich, J. C. de la Fuente, B. E. Gurkan, Z. K. Lopez, E. A. Price, Y. Huang and J. F. Brennecke, J. Phys. Chem. B, 2011, 115, 9140-9150.

49 F. Barzagli, M. Di Vaira, F. Mani and M. Peruzzini, ChemSusChem, 2012, 5, 1724-1731.

50 F. Barzagli, S. Lai, F. Mani and P. Stoppioni, Energy Fuels, 2014, 63, 1795-1804.

51 X. Y. Luo, Y. Guo, F. Ding, H. Q. Zhao, G. K. Cui, H. R. Li and C. M. Wang, Angew. Chem., Int. Ed., 2014, 53, 7053-7057. 